\title{
EFEKTIVITAS BUS TRANS PADANG SEBAGAI MODA TRANSPORTASI PUBLIK DI KOTA PADANG
}

\author{
Rezki Tri Ananda Putri ${ }^{1}$, Sri Mariya ${ }^{2}$ \\ Program Studi Geografi, \\ Fakultas Ilmu Sosial, Universitas Negeri Padang \\ Email : rezkitrianandap123gmail.com
}

\begin{abstract}
ABSTRAK
Penelitian ini bertujuan untuk menganalisis efektivitas Bus Trans Padang sebagai moda transportasi publik yang dilihat dari 5 aspek yaitu aksesibilitas, kapasitas, ketepatan waktu, keamanan dan kenyamanan, serta tarif atau harga. Data yang digunakan terdiri dari data primer dan sekunder. Data primer diperoleh melalui observasi dan wawancara terstruktur terhadap 60 orang responden yang dipilih secara acak (random). Sedangkan data sekunder diperoleh dari studi pustaka dan instansi terkait. Metode yang digunakan adalah teknik skoring dan pengkelasan sederhana. Kelas efektivitas antara lain Efektif, Cukup efektif, dan Tidak efektif. Hasil Penelitian ini menemukan bahwa Bus Trans Padang sebagai moda transportasi publik di Kota Padang adalah "Efektif" secara keseluruhan maupun pada tiap variabel. Persentase skor masing-masin variabel antara lain Aksesibilitas 96\%, Kapasitas 89\%, Ketepatan waktu 84\%, Keamanan dan kenyamanan 93\%, dan Tarif atau harga $100 \%$. Variabel Tarif atau harga adalah yang paling tinggi dengan nilai sempurna. Ini berarti tarif yang ditawarkan efektif dan terjangkau. Sebaliknya, variabel Ketepatan waktu adalah paling rendah di antara yang lainnya namun masih tergolong efektif. Barangkali ini perlu dievaluasi agar kedepannya pelayanan Trans Padang semakin efektif.
\end{abstract}

Kata Kunci : Efektivitas, Trans Padang, Transportasi

\begin{abstract}
This study aims to determine the effectiveness of the Trans Padang Bus as a mode of public transportation in the city of Padang, which is seen from 5 aspects namely accessibility, capacity, timeliness, safety and comfort, as well as tariff or price. The data used consists of primary and secondary data. Primary data obtained through observation and structured interviews of 60 random passengers. While secondary data were obtained from literature studies and related institutions. The method used is a simple scoring technique with effectiveness class that is Effective, Quite effective, and Not effective. The results of this study found that the Trans Padang Bus as a mode of public transportation in the city of Padang is "effective" overall and for each variable. Percentage score of each variable includes Accessibility 96\%, Capacity 89\%, Timeliness $84 \%$, Safety and comfort 93\%, and Tariff or price $100 \%$. The Tariff variable or price is the highest with a perfect score. This means that the tariff offered is effective and affordable. Conversely, the timeliness variable is the lowest among others but is still relatively effective. Perhaps this needs to be evaluated so that Trans Padang services will be more effective in the future.
\end{abstract}

Keyword : Effectiveness, Trans Padang, Transportation

${ }^{1}$ Mahasiswa Geografi, Fakultas Ilmu Sosial, Universitas Negeri Padang

${ }^{2}$ Dosen Geografi, Fakultas Ilmu Sosial, Universitas Negeri Padang 


\section{PENDAHULUAN}

Trans Padang adalah layanan angkutan massal bus rapid transit (BRT) di Kota Padang yang mulai beroperasi pada Februari 2014, dengan jumlah bus 15 unit bus dan jumlah halte 37 unit. Rute Trans Padang adalah Pasar Raya Padang - Lubuk Buaya dengan jarak $33 \mathrm{KM}$ dalam satu trayek dengan halte utama adalah halte Imam Bonjol. Seiring dengan kebutuhan penumpang, halte Trans Padang terus ditambah sehingga halte bus Trans Padang sampai Juni 2015 berjumlah 71 halte (UPT Trans Padang, 2015).

\begin{tabular}{lcr}
\multicolumn{2}{c}{ Berhasil atau tidaknya } \\
pemerintah dalam & mengatasi \\
permasalahan lalu lintas & dengan
\end{tabular} penciptaan sebuah layanan transportasi, sangat bergantung dari kualitas pelayanan yang ditawarkan. Kualitas layanan sangat menentukan antusias masyarakat dalam menggunakan layanan transportasi Trans Padang. Sehingga semakin banyak masyarakat yang menggunakan transportasi umum dan pertumbuhan jumlah pengguna kendaraan pribadi dapat ditekan. Sehingga perlu dilakukan penelitian tentang efektivitas Bus Trans Padang sebagai moda transportasi publik di Kota Padang, dilihat dari lima variabel, yakni aksesibilitas, kapasitas, ketepatn waktu, keamanan dan kenyamanan, serta tarif atau harga, melalui penelitian "Efektivitas Trans Padang sebagai Moda Transportasi Publik di Kota Padang”.

\section{METODE PENELITIAN}

Wilayah penelitian di jalur Koridor 1 (Pasar Raya - Lubuk Buaya ) Bus Trans Padang.

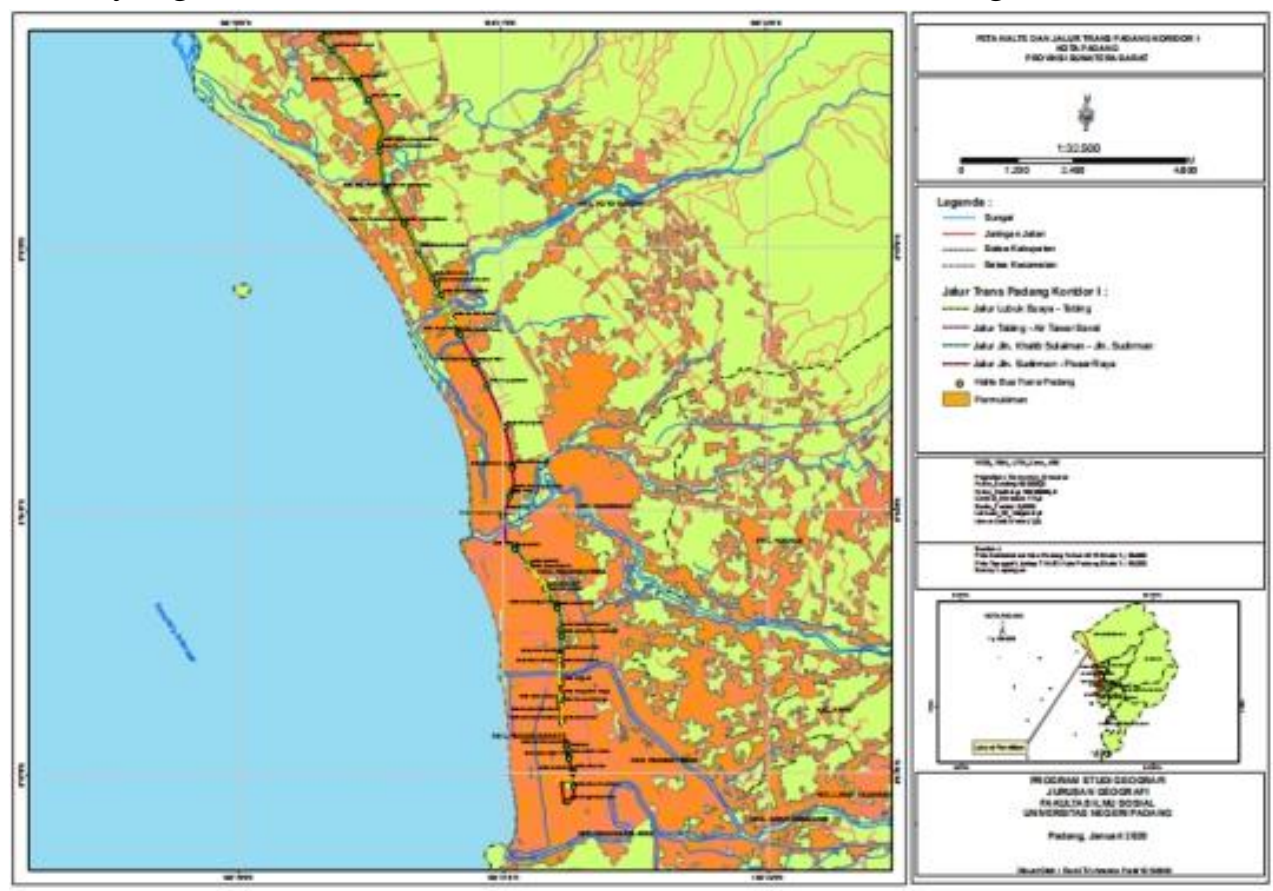

Gambar 1. Peta lokasi penelitian. 
Populasi dalam penelitian ini adalah seluruh pengguna Trans Padang koridor 1, terdiri dari pelajar, pekerja, dan masyarakat umum. Sampel penelitian sebanyak 60 orang pengguna Trans Padang yang dipilih secara acak (random). Pengumpulan data dilakukan melalui wawancara terstruktur dengan kuesioner.

Metode yang digunakan adalah deskriptif kuantitatif, dengan teknik skoring dan pengkelasan sederhana untuk mengetahui efektivitas dari pelayanan Trans Padang. Adapun komponen yang dianalisis dalam penelitian ini terdiri dari aksesibilitas, kapasitas, ketepatan waktu, keamanan dan kenyamanan, serta tarif atau harga tiket.

1. Aksesibilitas

Aksesibilitas yang dimaksud dalam hal ini yaitu kemudahan pergerakan penumpang menuju lokasi halte. Aksesibilitas ini berkaitan dengan penempatan lokasi halte apakah sesuai dengan permintaan (penumpang). Penempatan halte biasanya di titik keramaian seperti sekolah, kampus, kantor, pasar, dan lain-lain.

Tabel 1. Variabel Aksesibilitas Bus Trans Padang

\begin{tabular}{cccc}
\hline$(1)$ & $(2)$ & $(3)$ & $(4)$ \\
\hline No & Indikator & Harkat & Bobot \\
Indikator
\end{tabular}

1 Jarak menuju halte terdekat

A. Halte Trans Padang dapat diakses dengan jarak 3

kurang dari 100 meter

\begin{tabular}{ll}
\hline B. $100-300$ meter & 2 \\
\hline C. Lebih dari 300 meter & 1 \\
\hline
\end{tabular}

2 Transportasi pengumpan

A. Tidak memerlukan transportasi pengumpan 3

B. Memerlukan 1 kali transportasi pengumpan 2

0.6

C. Memerlukan lebih dari 1 kali transportasi 1 pengumpan

3 Penempatan halte

\begin{tabular}{ll}
\hline A. Lokasi halte strategis & 3 \\
\hline B. Lokasi halte cukup strategis & 2 \\
\hline C. Lokasi halte tidak strategis & 1
\end{tabular}

Sumber : Putrayasa, 2014 (disesuaikan) 
2. Kapasitas

Kapasitas Bus Trans Padang ukuran sedang berjumlah 40 orang dengan rincian 20 orang duduk dan 20 orang berdiri. Variabel kapasitas disini berkaitan dengan kesesuaian muatan dengan kapasitas. Indikator yang digunakan adalah sebagai berikut.

Tabel 2. Variabel Kapasitas

\begin{tabular}{|c|c|c|}
\hline (1) & (2) & (3) \\
\hline No & Indikator & Harkat \\
\hline \multirow[t]{4}{*}{1} & Kesesuaian muatan dengan kapasitas & \\
\hline & $\begin{array}{l}\text { A. Jumlah penumpang diisi sesuai kapasitas (maksimal } 40 \\
\text { orang) }\end{array}$ & 3 \\
\hline & B. Sedikit melebihi kapasitas (mencapai 45 orang) & 2 \\
\hline & C. Sangat sesak dan padat (lebih dari 45 orang) & 1 \\
\hline \multirow[t]{4}{*}{2} & Jumlah penumpang pagi & \\
\hline & A. Ramai, lebih dari separuh kapasitas hingga penuh & 3 \\
\hline & B. Cukup ramai, bus terisi separuh & 2 \\
\hline & C. Sepi, kurang dari separuh kapasitas & 1 \\
\hline \multirow[t]{4}{*}{3} & Jumlah penumpang siang & \\
\hline & A. Ramai, lebih dari separuh kapasitas hingga penuh & 3 \\
\hline & B. Cukup ramai, bus terisi separuh & 2 \\
\hline & C. Sepi, kurang dari separuh kapasitas & 1 \\
\hline \multirow[t]{4}{*}{4} & Jumlah penumpang sore & \\
\hline & A. Ramai, lebih dari separuh kapasitas hingga penuh & 3 \\
\hline & B. Cukup ramai, bus terisi separuh & 2 \\
\hline & C. Sepi, kurang dari separuh kapasitas & 1 \\
\hline
\end{tabular}

Sumber : Putrayasa, 2014 (disesuaikan)

3. Ketepatan waktu

Ketepatan waktu yang dimaksud adalah lama penumpang menunggu di halte, ketepatan waktu sampai tujuan, dan kesesuaian waktu keberangkatan. Hal tersebut dapat dilihat pada tabel berikut ini. 
Tabel 3. Variabel Ketepatan waktu

\begin{tabular}{|c|c|c|c|}
\hline (1) & (2) & (3) & (4) \\
\hline No. & Indikator & Harkat & Bobot Indikator \\
\hline 1 & Waktu tunggu di halte & & \multirow{12}{*}{0.6} \\
\hline & A. Penumpang menunggu di halte kurang dari 5 menit & 3 & \\
\hline & B. 5 sampai 10 menit & 2 & \\
\hline & C. Lebih dari 10 menit & 1 & \\
\hline \multirow[t]{4}{*}{2} & Ketepatan waktu sampai tujuan & & \\
\hline & A. Cepat, sampai lebih awal & 3 & \\
\hline & B. Normal & 2 & \\
\hline & C. Sedikit lebih lambat & 1 & \\
\hline \multirow[t]{4}{*}{3} & Kesesuaian waktu keberangkatan & & \\
\hline & A. Trans Padang sesuai waktu keberangkatan & 3 & \\
\hline & B. Cukup sesuai & 2 & \\
\hline & C. Tidak sesuai & 1 & \\
\hline
\end{tabular}

\section{Sumber : Putrayasa, 2014 (disesuaikan)}

4. Keamanan dan kenyamanan

Keamanan dan kenyamanan merupakan hal yang penting dan menjadi hak konsumen (penumpang). Adapun 5 hal penting terkait dengan keamanan dan kenyamanan yang dinilai dalam penelitian ini antara lain yaitu kebersihan dan kerapian, keramahan pelayanan, kondisi fasilitas fisik, keamanan, serta kenyamanan. Seperti yang ditampilkan pada tabel berikut.

Tabel 4. Keamanan dan kenyamanan

\begin{tabular}{|c|c|c|c|}
\hline (1) & (2) & (3) & (4) \\
\hline No. & Indikator & Harkat & $\begin{array}{c}\text { Bobot } \\
\text { Indikator }\end{array}$ \\
\hline 1 & Kebersihan dan kerapian & & \multirow{12}{*}{0.36} \\
\hline & A. Bus Trans Padang bersih dan rapi & 3 & \\
\hline & B. Cukup bersih dan rapi & 2 & \\
\hline & C. Tidak bersih dan tidak rapi & 1 & \\
\hline \multirow[t]{4}{*}{2} & Keramahan pelayanan & & \\
\hline & A. Pramugara sangat ramah melayani penumpang & 3 & \\
\hline & A. Pramugara ramah melayani penumpang & 2 & \\
\hline & A. Pramugara tidak ramah melayani penumpang & 1 & \\
\hline \multirow[t]{4}{*}{3} & Kondisi fasilitas fisik & & \\
\hline & A. Memadai, fasilitas berfungsi dengan baik & 3 & \\
\hline & $\begin{array}{l}\text { B. Kurang memadai, satu atau beberapa fasilitas tidak } \\
\text { berfungsi (rusak ringan) }\end{array}$ & 2 & \\
\hline & C. Tidak memadai, banyak fasilitas yang tidak berfungsi & 1 & \\
\hline
\end{tabular}


Lanjutan tabel 4

\begin{tabular}{lll}
\hline 4 & Kenyamanan penumpang & \\
\hline & A. Penumpang merasa nyaman berada di bus & 3 \\
\hline & B. Penumpang merasa kurang nyaman & 2 \\
\hline & C. Penumpang merasa tidak nyaman & 1 \\
\hline 5 & Keamanan & 3 \\
\hline & A. Penumpang merasa aman berada di bus & 2 \\
\hline & B. Penumpang merasa kurang aman & 1
\end{tabular}

Sumber: Putrayasa, 2014 (disesuaikan)

5. Tarif atau harga

Untuk menentukan tarif atau harga dari tiket Bus Trans Padang mengacu kepada standar yang sudah ditetapkan oleh pemerintah, kemudain menanyakan langsung kepada penumpang apakah tarif atau harga tiket tersebut telah memenuhi atau sesuai dengan keterjangkauan oleh para penumpang. Selain itu, juga dianalisis tingkat kepuasan penumpang yang dilihat dari kesesuaian tarif dengan pelayanan yang diberikan serta dengan membandingkan tarif Trans Padang dengan moda transportasi lain.

Tabel 5. Tarif atau harga

\begin{tabular}{lll}
\hline \multicolumn{1}{c}{$(1)$} & \multicolumn{1}{c}{$(2)$} & $(3)$ \\
\hline No. & & Harkat \\
& & \\
\hline 1 & Keterjangkauan harga tiket & 3 \\
\hline & A. Harga tiket terjangkau & 2 \\
\hline & B. Harga tiket cukup terjangkau & 1 \\
\hline & C. Tidak terjangkau & 3 \\
\hline 2 & Kesesuaian tarif dengan pelayanan yang diberikan & 2 \\
\hline & A. Tarif sesuai dengan pelayanan & 1 \\
\hline & B. Cukup sesuai & 3 \\
\hline 3 & C. Tarif tidak sesuai dengan pelayanan & 2 \\
\hline & Perbandingan harga tarif dengan angkutan lain & 1 \\
\hline & B. Tarif Trans Padang lebih murah daripada angkutan lain \\
\hline
\end{tabular}

Sumber : Putrayasa, 2014 (disesuaikan)

Penentuan tingkat efektivitas bus trans Padang sebagai moda transportasi umum dilakukan dengan menjumlahkan setiap jawaban yang diberikan dengan menentukan kelas interval sebagai berikut. 


\begin{tabular}{|c|c|}
\hline \multirow{2}{*}{$\boldsymbol{i}=$} & $X t-X r$ \\
\cline { 2 - 2 } & $k$ \\
\hline
\end{tabular}

Keterangan

i : nilai interval

Xt : harkat tertinggi (jika semua jawaban tinggi, skor $=1620$ )

$\mathrm{Xr}$ : harkat terendah (jika semua jawaban rendah, skor $=540$ )

k : jumlah kelas

Peneliti menetapkan 3 kelas efektivitas, berturut-turut dari yang tertinggi yakni "Efektif", "Cukup efektif”, dan “Tidak efektif". Berdasarkan persamaan, maka interval kelasnya:

\begin{tabular}{|c|c|}
\hline \multirow{2}{*}{$\mathrm{i}=$} & $1620-540$ \\
\cline { 2 - 2 } & 3 \\
\hline
\end{tabular}

$\mathrm{i}=360$

Dengan interval 300, klasifikasi Efektivitas dapat dibuat sebagai berikut.

-Efektif, jika skor akhir 1260 - 1620

-Cukup efektif, skor 900 - 1260

-Tidak efektif, dengan skor 540 900

\section{HASIL PENELITIAN}

1. Aksesibilitas

Variabel aksesibilitas pada penelitian ini dapat dilihat pada tabel di bawah ini.

Tabel 6. Efektivitas Trans Padang dari Segi Aksesibilitas

\begin{tabular}{|c|c|c|c|c|c|c|}
\hline (1) & (2) & (3) & (4) & (5) & (6) & (7) \\
\hline No. & Indikator & Harkat & $\begin{array}{c}\text { Bobot } \\
\text { Indikator }\end{array}$ & Responden & Persentase & $\begin{array}{c}\text { Skor } \\
(3) \times(4) \times(5)\end{array}$ \\
\hline \multirow[t]{5}{*}{1} & $\begin{array}{l}\text { Jarak menuju halte } \\
\text { terdekat }\end{array}$ & & 0.6 & & & \\
\hline & $\begin{array}{l}\text { A. Halte Trans Padang } \\
\text { dapat diakses dengan }\end{array}$ & 3 & & 48 & 80 & 86.4 \\
\hline & $\begin{array}{l}\text { jarak kurang dari } 100 \\
\text { meter }\end{array}$ & & & & & \\
\hline & B. $100-300$ meter & 2 & & 9 & 15 & 10.8 \\
\hline & $\begin{array}{l}\text { C. Lebih dari } 300 \\
\text { meter }\end{array}$ & 1 & & 3 & 5 & 1.8 \\
\hline \multirow[t]{4}{*}{2} & $\begin{array}{l}\text { Transportasi } \\
\text { pengumpan }\end{array}$ & & & & & \\
\hline & $\begin{array}{l}\text { A. Tidak memerlukan } \\
\text { transportasi } \\
\text { pengumpan }\end{array}$ & 3 & & 56 & 93 & 100.8 \\
\hline & $\begin{array}{l}\text { B. Memerlukan } 1 \text { kali } \\
\text { transportasi } \\
\text { pengumpan }\end{array}$ & 2 & & 4 & 7 & 4.8 \\
\hline & $\begin{array}{l}\text { C. Memerlukan lebih } \\
\text { dari } 1 \text { kali transportasi }\end{array}$ & 1 & & - & & - \\
\hline
\end{tabular}


Lanjutan tabel 6

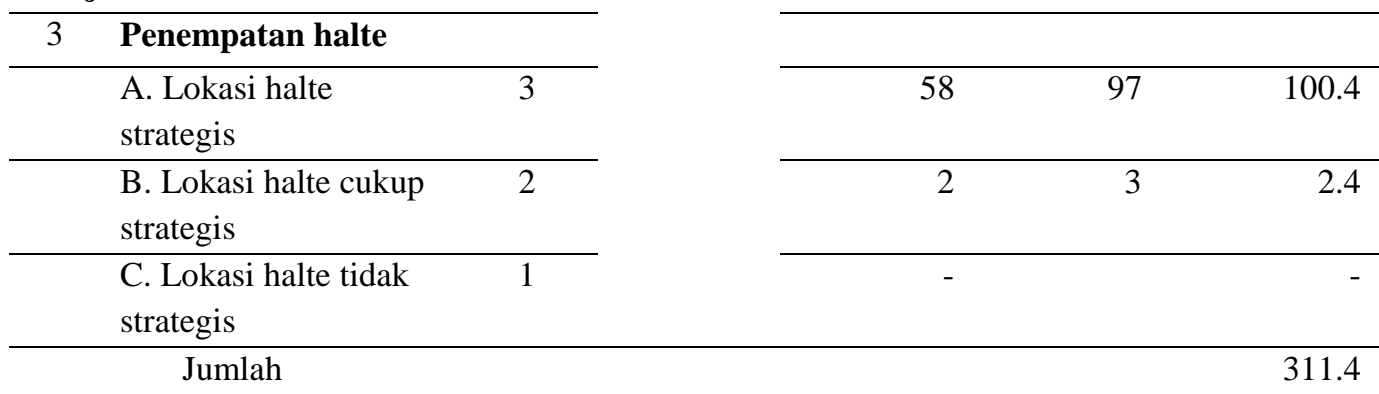

Sumber: Olah Data Primer (2019)

Berdasarkan tabel di atas, variabel aksesibiltas dalam penelitian ini di bentuk oleh 3 indikator, Pertama jarak menuju halte, 48 responden $(80 \%)$ menjawab halte Bus Trans Padang dapat di akses dengan jarak kurang dari 100 meter. Ada juga 9 responden (15\%) menjawab 100 - 300 meter, dan sisanya 3 responden $(5 \%)$ menjawab lebih dari 300 meter.

Kedua kebutuhan transportasi pengumpan, mengingat Trans Padang saat ini hanya ada satu koridor aktif. Hasilnya 56 responden (93\%) mengaku tidak memerlukan transportasi pengumpan menuju halte Bus Trans Padang, dan sisanya 4 responden (7\%) mengaku memerlukan satu kali transportasi pengumpan. Tidak satupun responden memerlukan lebih dari satu transportasi pengumpan. Ini berarti 14 dari 15 responden bertempat tinggal di sekitar jalur Trans Padang, sehingga tidak memerlukan

transportasi

pengumpan.

Indikator yang terakhir adalah penempatan halte. Meskipun sebelumnya sudah direncanakan dengan matang, penempatan halte dapat dikatakan strategis apabila dapat di akses dengan mudah oleh penumpang. Hasil wawancara dengan 60 responden menemukan bahwa sebanyak 58 responden (97\%) mengatakan lokasi halte strategis. Sisanya 2 orang (3\%) mengatakan cukup strategis. Sejalan dengan dua indikator sebelumnya, yang berkaitan, lokasi halte memang terbilang strategis. Karena secara umum dapat diakses dalam jarak kurang lebih 100 meter serta tidak memerlukan transportasi pengumpan. Total skor keseluruhan adalah 311.4 dan termasuk efektif.

\section{Kapasitas}

Analisis kapasitas dapat dilihat pada tabel di bawah ini. 
Tabel 7. Kesesuaian Kapasitas Bus Trans Padang

\begin{tabular}{|c|c|c|c|c|c|c|}
\hline (1) & (2) & (3) & (4) & (5) & (6) & (7) \\
\hline No. & Indikator & Harkat & $\begin{array}{c}\text { Bobot } \\
\text { Indikator }\end{array}$ & Responden & Persentase & $\begin{array}{c}\text { Skor } \\
(3) \mathrm{x}(4) \mathrm{x}(5)\end{array}$ \\
\hline 1 & Kesesuaian muatan dengan kapasitas & & \multirow{16}{*}{0.45} & & & \\
\hline & A. Jumlah penumpang diisi sesuai kapasitas (maksimal 40 orang) & 3 & & 60 & 100 & 81 \\
\hline & B. Sedikit melebihi kapasitas (mencapai 45 orang) & 2 & & - & - & \\
\hline & C. Sangat sesak dan padat (lebih dari 45 orang) & 1 & & - & - & \\
\hline 2 & Jumlah penumpang (pagi) & & & & & \\
\hline & A. Ramai, lebih dari separuh kapasitas hingga penuh & 3 & & 60 & 100 & 81 \\
\hline & B. Cukup ramai, bus terisi separuh & 2 & & - & - & \\
\hline & C. Sepi, kurang dari separuh kapasitas & 1 & & - & & - \\
\hline \multirow[t]{4}{*}{3} & Jumlah penumpang (siang) & & & & & \\
\hline & A. Ramai, lebih dari separuh kapasitas hingga penuh & 3 & & - & - & - \\
\hline & B. Cukup ramai, bus terisi separuh & 2 & & 45 & 75 & 40.5 \\
\hline & C. Sepi, kurang dari separuh kapasitas & 1 & & 15 & 25 & 6.75 \\
\hline \multirow[t]{4}{*}{4} & Jumlah penumpang (sore) & & & & & \\
\hline & A. Ramai, lebih dari separuh kapasitas hingga penuh & 3 & & 60 & 100 & 81 \\
\hline & B. Cukup ramai, bus terisi separuh & 2 & & - & - & - \\
\hline & C. Sepi, kurang dari separuh kapasitas & 1 & & - & - & - \\
\hline
\end{tabular}

Sumber : Olah Data Primer (2019) 
Wawancara dengan 60 penumpang, semuanya mengatakan bahwa bus diisi sesuai dengan kapasitas pada saat penuh, yakni 40 orang. Artinya mereka menyaksikan pengisian bus sesuai standar operasi yang ditetapkan.

Tiga indikator lainnya terkait kesesuaian muatan dengan kapasitas yang dilihat pada waktu pagi, siang dan sore hari. Karena secara umum, waktu-waktu ini merupakan peak hours dimana mobilitas sangat tinggi. Pada saat pagi dan sore hari, semua responden mengatakan bahwa penumpang bus ramai, yakni lebih dari setengah hingga penuh. Beberapa di antaranya bahkan mengatakan kalau bus Trans Padang selalu penuh saat pagi dan sore hari. Rozy (33) mengatakan "saya hampir setiap hari pulang pergi ke tempat kerja naik Bus Trans Padang, dan itu selalu penuh.“
Sementara pada siang hari, 45 responden $(75 \%)$ mengatakan kalau Bus Trans Padang umumnya terisi separuh. Sisanya 15 responden (25\%) kurang dari separuh. Tidak satupun dari mereka yang mengatakan Bus Trans Padang penuh pada siang hari. Ini menunjukan bahwa mobilitas pada siang hari tidak sepadat saat pagi dan sore hari.

Total skor keseluruhan variabel ini adalah 290,25 yang berarti masuk kategori efektif. Jika dibandingkan dengan nilai sempurna yakni 324, maka efektivitasnya adalah $89 \%$.

3. Ketepatan waktu

Perhitungan variabel ketepatan waktu dapat dilihat pada tabel di bawah ini

Tabel 8. Ketepatan waktu Bus Trans Padang

\begin{tabular}{|c|c|c|c|c|c|c|}
\hline (1) & (2) & (3) & (4) & (5) & (6) & (7) \\
\hline No. & Indikator & Harkat & $\begin{array}{c}\text { Bobot } \\
\text { Indikator }\end{array}$ & Responden & Persentase & $\begin{array}{c}\text { Skor } \\
(3) \mathrm{x}(4) \mathrm{x}(5)\end{array}$ \\
\hline 1 & Waktu tunggu di halte & & \multirow{8}{*}{0.6} & & & \\
\hline & $\begin{array}{l}\text { A. Penumpang } \\
\text { menunggu di halte } \\
\text { kurang dari } 5 \text { menit }\end{array}$ & 3 & & 51 & 85 & 91.8 \\
\hline & B. 5 sampai 10 menit & 2 & & 8 & 13.3 & 9.6 \\
\hline & C. Lebih dari 10 menit & 1 & & 1 & 1.7 & 0.6 \\
\hline \multirow[t]{4}{*}{2} & $\begin{array}{l}\text { Ketepatan waktu } \\
\text { sampai tujuan }\end{array}$ & & & & & \\
\hline & $\begin{array}{l}\text { A. Cepat, sampai lebih } \\
\text { awal }\end{array}$ & 3 & & 3 & 5 & 5.4 \\
\hline & B. Normal & 2 & & 56 & 93.3 & 67.2 \\
\hline & C. Sedikit lebih lambat & 1 & & 1 & 1.7 & 0.6 \\
\hline
\end{tabular}


Lanjutan tabel 8

\begin{tabular}{|c|c|c|c|c|c|}
\hline \multirow[t]{2}{*}{3} & \multicolumn{5}{|l|}{$\begin{array}{l}\text { Kesesuaian waktu } \\
\text { keberangkatan }\end{array}$} \\
\hline & $\begin{array}{l}\text { A. Trans Padang sesuai } \\
\text { waktu keberangkatan }\end{array}$ & 3 & 42 & 70 & 75.6 \\
\hline & B. Cukup sesuai & 2 & 18 & 30 & 21.6 \\
\hline & C. Tidak sesuai & 1 & - & & - \\
\hline & Jumlah & & & & 272.4 \\
\hline
\end{tabular}

Sumber : Olah Data Primer (2019)

Terdapat 3 indikator yang di

Sementara itu, indikator yang analisis dalam variabel ketepatan waktu, yakni waktu tunggu di halte, ketepatan waktu sampai di tempat tujuan dan kesesuaian waktu keberangkatan. Untuk waktu tunggu di halte, sebanyak 51 responden (85\%) menjawab kurang dari 5 menit, 8 responden $(13,3 \%)$ menjawab 5 sampai 10 menit, dan sisanya 1 responden $(1,7 \%)$ menjawab lebih dari 10 menit. Ini berarti secara rata-rata, 5 dari 6 penumpang tidak masalah dengan waktu tunggu.

Indikator selanjutnya, yakni ketepatan waktu sampai tujuan, ada 3 responden $(5 \%)$ yang mengatakan bahwa menggunakan Bus Trans Padang lebih cepat sampai tujuan, 56 responden (93,3\%) menjawab normal atau sama dengan angkutan lain maupun kendaraan pribadi. Hanya 1 responden (1,7\%) yang menjawab sedikit lebih lambat.

ketiga yaitu kesesuaian waktu keberangkatan. Maksudnya adalah kemunculan Bus Trans Padang sesuai dengan yang di jadwalkan sebelumnya dengan selang waktu 5 menit antara bus yang satu dengan bus berikut. Hasilnya adalah 42 responden $(70 \%)$ menjawab sesuai, sisanya 18 responden $(30 \%)$ menjawab cukup sesuai.

Total skor variabel ini adalah 272.4 yang menjadikannya termasuk kategori efektif. Jika dibandingkan dengan skor tertinggi yakni 324 maka persentasenya adalah $84 \%$. Artinya, ketepatan waktu Bus Trans Padang adalah $84 \%$ dalam lingkup penelitian ini.

4. Keamanan dan kenyamanan

Perhitungan keamanan dan kenyamanan dapat dilihat pada tabel di bawah ini 
Tabel 9. Keamanan dan Kenyamanan Bus Trans Padang

\begin{tabular}{|c|c|c|c|c|c|c|}
\hline (1) & (2) & (3) & (4) & (5) & (6) & (7) \\
\hline No. & Indikator & Harkat & Bobot & Responden & Persentase & Skor \\
\hline \multirow[t]{4}{*}{1} & Kebersihan dan kerapian & & 0.36 & & & \\
\hline & A. Bus Trans Padang bersih dan rapi & 3 & & 60 & 100 & 64.8 \\
\hline & B. Cukup bersih dan rapi & 2 & & - & - & - \\
\hline & C. Tidak bersih dan tidak rapi & 1 & & - & - & - \\
\hline \multirow[t]{4}{*}{2} & Keramahan pelayanan & & & & & \\
\hline & A. Pramugara sangat ramah melayani penumpang & 3 & & 3 & 5 & 3.24 \\
\hline & B. Pramugara ramah melayani penumpang & 2 & & 54 & 90 & 38.88 \\
\hline & C. Pramugara tidak ramah melayani penumpang & 1 & & 3 & 5 & 1.08 \\
\hline \multirow[t]{4}{*}{3} & Kondisi fasilitas fisik & & & & & \\
\hline & A. Memadai, fasilitas berfungsi dengan baik & 3 & & 59 & 98.3 & 63.72 \\
\hline & B. Kurang memadai, satu atau beberapa fasilitas tidak berfungsi & 2 & & 1 & 1.7 & 0.72 \\
\hline & C. Tidak memadai, banyak fasilitas yang tidak berfungsi (rusak berat) & 1 & & - & - & - \\
\hline \multirow[t]{4}{*}{4} & Kenyamanan penumpang & & & & & \\
\hline & A. Penumpang merasa nyaman berada di bus & 3 & & 60 & 100 & 64.8 \\
\hline & B. Penumpang merasa kurang nyaman & 2 & & - & - & - \\
\hline & C. Penumpang merasa tidak nyaman & 1 & & - & - & - \\
\hline \multirow[t]{5}{*}{5} & Keamanan & & & & & \\
\hline & A. Penumpang merasa aman berada di bus & 3 & & 60 & 100 & 64.8 \\
\hline & B. Penumpang merasa kurang aman & 2 & & - & - & - \\
\hline & C. Penumpang merasa tidak aman & 1 & & - & - & - \\
\hline & Jumlah & & & & & 302.04 \\
\hline
\end{tabular}


Ada lima indikator yang dinilai dari variabel ini yaitu kebersihan dan kerapian, keamahan pelayanan, kondisi fasilitas fisik, kemananan, serta kenyamanan. Seperti yang terlihat pada tabel diatas, 3 dari 5 indikator memiliki nilai sempurna. Indikator tersebut antara lain kebersihan dan kerapian, keamanan, dan kenyamanan. Semua responden menyatakan bahwa Bus Trans Padang bersih dan rapi, aman dan juga nyaman.

Sementara itu dari indikator keramahan pelayanan, 54 responden (90\%) mengatakan pramugara Bus Trans Padang ramah dalam melayani penumpang. Hanya ada 3 responden (5\%) yang mengatakan sangat ramah, dan 3 reponden lagi (5\%) menagatakan tidak ramah. Hal ini sangat menjadi perhatian yang meskipun hanya 5\%, 3 dari 50 responden merasa pramugara tidak ramah dalam melayani penumpang. Sebaliknya, hanya ada 3 responden yang menyatakan pramugara sangat ramah. Artinya dari segi keramahan pelayanan, Trans Padang memang belum maksimal dan terkesan biasa saja.

Untuk kondisi fisik 59 responden (98.3\%) menyatakan fasilitas bus dalam kondisi baik. Sisanya 1 responden $(1.7 \%)$ menyatakan satu atau beberapa fasilitas fisik tidak berfungsi atau rusak ringan. Lagi-lagi ini menjadi perhatian yang walaupun perbandingannya hanya $1.7 \%$ responden, akan tetapi ini berkaitan dengan standar operasi dan kelayakan fasilitas yang harus dijaga. Total skor keseluruhan variabel ini adalah 302,04 yang juga termasuk kategori efektiv. Dengan kata lain, keamanan dan kenyamanan Bus Trans Padang adalah 93\% dalam lingkup penelitian ini.

\section{Tarif atau harga}

Perhitungan tarif atau harga dalam penelitian ini dapat dilihat pada tabel di bawah ini. 
Tabel 10. Efektivitas Tarif Bus Trans Padang

\begin{tabular}{|c|c|c|c|c|c|c|}
\hline (1) & (2) & (3) & (4) & (5) & (6) & (7) \\
\hline No. & Indikator & Harkat & $\begin{array}{c}\text { Bobot } \\
\text { Indikator }\end{array}$ & Responden & Persentase & $\begin{array}{c}\text { Skor } \\
(3) \mathrm{x}(4) \mathrm{x}(5)\end{array}$ \\
\hline \multirow[t]{4}{*}{1} & $\begin{array}{l}\text { Keterjangkauan } \\
\text { harga tiket }\end{array}$ & & 0.6 & & & \\
\hline & $\begin{array}{l}\text { A. Harga tiket } \\
\text { terjangkau }\end{array}$ & 3 & & 60 & 100 & 108 \\
\hline & $\begin{array}{l}\text { B. Harga tiket } \\
\text { cukup terjangkau }\end{array}$ & 2 & & - & - & - \\
\hline & $\begin{array}{l}\text { C. Tidak } \\
\text { terjangkau }\end{array}$ & 1 & & - & - & - \\
\hline \multirow[t]{4}{*}{2} & $\begin{array}{l}\text { Kesesuaian tarif } \\
\text { dengan } \\
\text { pelayananyang } \\
\text { diberikan }\end{array}$ & & & & & \\
\hline & $\begin{array}{l}\text { A. Tarif sesuai } \\
\text { dengan pelayanan }\end{array}$ & 3 & & 60 & 100 & 108 \\
\hline & B. Cukup sesuai & 2 & & - & - & - \\
\hline & $\begin{array}{l}\text { C. Tarif tidak } \\
\text { sesuai dengan } \\
\text { pelayanan }\end{array}$ & 1 & & - & - & - \\
\hline \multirow[t]{5}{*}{3} & $\begin{array}{l}\text { Perbandingan } \\
\text { harga tarif } \\
\text { dengan angkutan } \\
\text { lain }\end{array}$ & & & & & \\
\hline & $\begin{array}{l}\text { A. Tarif Trans } \\
\text { Padang lebih } \\
\text { murah dari pada } \\
\text { angkutan lain }\end{array}$ & 3 & & 60 & 100 & 108 \\
\hline & $\begin{array}{l}\text { B. Tarif Trans } \\
\text { Padang sama } \\
\text { dengan angkutan } \\
\text { lain }\end{array}$ & 2 & & - & - & - \\
\hline & $\begin{array}{l}\text { C. Tarif Trans } \\
\text { Padang lebih } \\
\text { mahal daripada } \\
\text { angkutan lain }\end{array}$ & 1 & & - & - & - \\
\hline & Jumlah & & & & & 324 \\
\hline
\end{tabular}

Sumber: Olah Data Primer (2019) 
Seperti yang terlihat pada tabel di atas, semua responden menyatakan bahwa tarif Bus Trans Padang adalah terjangkau. Para responden merasa bahwa tarif yang ditetapkan sesuai dengan pelayanan yang di berikan. Selain itu, tarif Bus Trans Padang juga lebih murah dari pada angkutan lain. Jawaban sempurna ini menunjukan bahwa dari segi tarif Bus Trans Padang memang "efektif."

\section{Efektivitas}

Penentuan efektivitas Bus Trans Padang sebagai moda transportasi publik di Kota Padang berdasarkan kelima variabel sebelumnya dapat dirumuskan sebagai berikut.

Tabel 11. Efektivitas Moda Bus Trans Padang

\begin{tabular}{llccl}
\hline No & \multicolumn{1}{c}{ Variabel } & $\begin{array}{c}\text { Total } \\
\text { Bobot }\end{array}$ & Persentase & Klasifikasi \\
\hline $\mathbf{1}$ & Aksesibilitas & 311,4 & 96 & Efektif \\
\hline $\mathbf{2}$ & Kapasitas & 290,25 & 89 & Efektif \\
\hline $\mathbf{3}$ & Ketepatan Waktu & 272,4 & 84 & Efektif \\
\hline $\mathbf{4}$ & Keamanan dan Kenyamanan & 302,04 & 93 & Efektif \\
\hline $\mathbf{5}$ & Tarif Harga & 324 & 100 & Efektif \\
\hline & Jumlah & 1500,45 & 92 & Efektif
\end{tabular}

Sumber: Olah Data Primer (2019)

Penjumlahan bobot semua variabel mendapati skor 1.500,45. Berdasarkan klasifikasi yang telah ditetapkan, maka hasilnya tergolong "Efektif." Tabel di atas dapat dibuat diagram radar untuk memudahkan dalam mengamati suatu pemisahan logis antara variabel-variabel yang akan dibandingkan. Dalam diagram ini terlihat karakteristik objek terhadap variabel-variabel yang ada (Lestari: 2005).

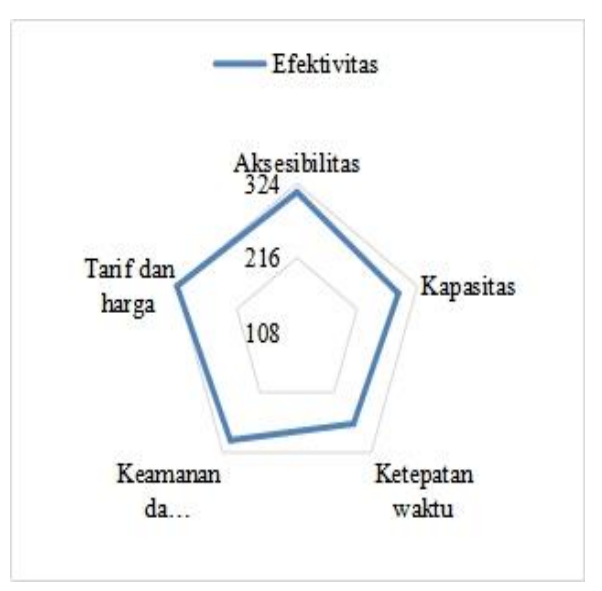

Gambar 2. Diagram Radar Efektivitas Bus Trans Padang 
Diagram di atas menunjukkan bagaimana Efektivitas Bus Trans Padang sebenarnya sudah terlihat dari nilai masing-masing variabel yang sangat baik. Persentase efektivitas keseluruhan adalah 92\%. Artinya, efektivitas Bus Trans Padang sebagai moda Transportasi publik di Kota Padang adalah 92\% dalam lingkup penelitian ini.

Akan tetapi, ada dua variabel yang menjadi perhatian disini yaitu Ketepatan waktu dan Kapasitas. Meskipun memiliki nilai yang tinggi dan termasuk efektif, keduanya tetap lebih rendah dibanding yang lainnya. Barangkali ini perlu dievaluasi dan dianalisis lebih lanjut agar kedepannya pelayanan Bus Trans Padang semakin "Efektif."

\section{KESIMPULAN}

Berdasarkan hasil penelitian terebut mengenai ke efektivitas bus trans padang sebagai moda transportasi publik di kota padang dapat disimpulkan sebagai berikut : (a) Dari segi aksesibiltas, halte bus Trans Padang secara umum terjangkau dalam jarak 100 meter. Hal ini karena penempatannya yang efektif di pusat-pusat keramaian dan fasilitas publik. (b) Kapasitasnya sesuai, artinya pada saat ramai jumlah penumpang tidak melebihi kapasitas yang ditetapkan, yakni sebanyak 40 orang. Pelaksanaannya cukup tertib sesuai standar operasi. Pagi dan sore hari merupakan waktu paling efektif karena umumnya bus terisi penuh. Pada siang hari rata-rata bus terisi separuh kapasitas berkisar 15 sampai 20 orang. (c) Ketepatan waktu juga terbilang "Tepat." Meskipun demikian, variabel ini paling rendah di antara yang lainnya. Ini perlu evaluasi supaya kedepannya pelayanan Trans Padang lebih efektif. (d) Dari segi keamanan dan kenyamanan, tidak diragukan lagi Trans Padang adalah transportasi yang aman dan nyaman. Ini terutama karena fasilitas yang cukup lengkap, bebas dari polusi asap rokok, serta pelayanan yang tertib. (e) Tarif yang ditetapkan terjangkau, lebih murah dibandingkan angkutan umum biasa. Harga tiket juga stabil serta tidak dipengaruhi kenaikan harga bahan bakar.

Secara keseluruhan, efektivitas Bus Trans Padang sebagai moda Transportasi publik di Kota Padang adalah $92 \%$ dalam lingkup penelitian ini.

\section{DAFTAR PUSTAKA}

Dwiyanto, Agus. 2005. Mewujudkan

Good Governance Melalui Pelayanan Publik.

Yogyakarta : Pustaka Sinar Harapan.

Haryoto, Edie. 2013. Transportasi Pro Rakyat. Jakarta: Pt Gramedia Pustaka Utama.

Lukman, Sampara. 2004. Manajemen Kualitas Pelayanan. Jakarta : Stia Lanpress. Ningtyas Dan Joewono, 2009. (Bus Rapid Transit, Brt) 
Khisty, C. Jotin Dan B. Kent

Lall. 2003. Dasar-Dasar Rekayasa Transportasi/Edisi Ke-3/Jilid 2. Jakarta: Erlangga.

Mardalis, 2010 Jenis Penelitian Kualitatif, Jakarta

Majid, Suharto Abdul. 2009. Customer Service Dalam Bisnis Jasa Transportasi. Jakarta : Pt Rajagrafindo Persada.

Nurmandi, Achmad. 2010. Manajemen Pelayanan Publik. Yogyakarta : Sinergi Publising.

Rini, Indri Nurvia Puspita. 2007. Analisis Persepsi Penumpang Terhadap Tingkat Pelayanan Busway. Semarang: Universitas Diponegoro.

Salim, Abbas S.E., M.A., Drs. H.A. 2008. Manajemen

Transportasi. Jakarta: Pt. Raja Grafindo.

Sugiyono Prof. Dr. 2012. Metode Penelitian
Pendidikan: Pendekatan

Kuantitatif, Kualitatif, Dan

$R \& D$. Bandung: Alfabeta, $\mathrm{Cv}$.

Syukri, Agus Fanar. 2009. Standar Pelayanan Publik Pemda. Bantul : Kreasiwacana.

Dwiyanto, Agus. 2005. Mewujudkan Good Governance Melalui Pelayanan Publik. Yogyakarta : Pustaka Sinar Harapan.

Putra, I Gusti Agung Bagus Angga. 2016. Studi Evaluasi Program Bus Trans Sarbagita Pemerintah Provinsi Bali. JurnalKebijakan dan Manajemen Publik, 4 (1).

Putrayasa,I Made Agus, dan Ni Kadek Sri Maharani.2014. Efektivitas Bus Trans Sarbagita Trayek Kota GWK Dalam Mengurangi Kemacetan Di Kota Denpasar Dan Kabupaten Badung. Soshum Jurnal Sosial dan Humaniora, 4 (1), hal.12-23. 